\title{
Study on Torque Distribution of Master and Auxiliary Motor Coupled Driving System
}

\author{
Jinrui Nan, Wang Zhai, Hongliang Lin, Zi Yang \\ Beijing Institute of Technology, Collaborative Innovation Center of Electric Vehicles in Beijing, Beijing, \\ 100081, China
}

\begin{abstract}
This paper focused on the torque distribution of master and auxiliary motor coupled driving system for the pure electric vehicle. With the minimum consumption of power as the target, the equivalent PESCM method was employed. The torque split maps of master and auxiliary motor were obtained .The simulation model was built in MATLAB/Simulink and the simulation was carried out .Both the results of simulation and tests indicate the strategy can realize the rational torque distribution, more than double motor independent drive and equal torque drive to expand the efficient working range, improve the energy conversation potential.
\end{abstract}

KEYWORD: electric vehicle; master and auxiliary motor; torque distribution; energy conversation potential

\section{INTRODUCTION}

Use The multi power coupling drive system can coordinate the work characteristics of each power source, and optimize the overall efficiency and driving characteristics of the drive system to improve the performance of the electric vehicle (Bo Zhu, 2013). As one of the key technologies in multi power coupling drive system, integrated control system of multi power general according to the driver and vehicle operation condition information, determine the corresponding vehicle work state, after in to specific conditions for power distribution system power components. It pays for signal collection, driver intention recognition, energy distribution and control command output and other important functions, its performance directly affects the economy and power performance of vehicle.

Xiao Hua $\mathrm{Wu}(\mathrm{Wu}$ Xiaohua, 2013)et al studied a dual motor coupling motor drive system based on torque control strategy, the system is divided into a single motor at low speed and high speed double motor model, at the same time it can realize the different patterns of recognition and model in the process of switching control strategy; Wang Jun, (WANG Jun-nian, 2016)etc. are directed to a method of enabling simultaneous torque coupling and speed coupling the new drive configuration was introduced, and the analysis of its structural features, and its parameter matching and control strategy.

\section{CONFIGURATION OF MASTER AND AUXILIARY MOTOR COUPLING DRIVE SYSTEM}

Previous research focused on the analysis of the structure of the new configuration, and identification of different driving modes and control strategy research in the process of transformation, less discussed specific mode torque distribution between the different power sources (GAO Jian-ping, 2008). The idea of torque distribution algorithm reference hybrid vehicle fuel consumption equivalent method, which used the instantaneous optimization algorithm based on the motor efficiency optimal, the optimal algorithm of computing the minimum motor power demand with minimal power operating point to a reasonable allocation of two torque motors.

Figure 1 shows for the study of the master and auxiliary motor coupling drive system configuration, the master motor and the transmission assembly always be hard-wired, while the auxiliary motor is an electric clutch, through the separation and combination of that can realize the individual drive motor and main motor torque coupling operation condition, etc. 


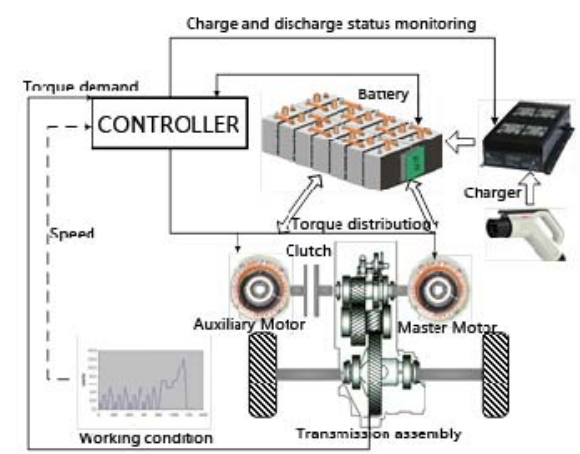

Figure 1. Configuration of Master and auxiliary motor coupling drive system.

Table 1. Motor torque output.

\begin{tabular}{ccccccccccc}
$\begin{array}{c}\text { Torque } \\
\text { demand }\end{array}$ & $10 \%$ & $20 \%$ & $30 \%$ & $40 \%$ & $50 \%$ & $60 \%$ & $70 \%$ & $80 \%$ & $90 \%$ & $100 \%$ \\
\cline { 1 - 10 } \begin{tabular}{c} 
Motor speed \\
\hline 500
\end{tabular} & 14.3 & 28.5 & 42.8 & 57.1 & 71.4 & 85.6 & 99.9 & 114.2 & 128.4 & 142.7 \\
\hline 1000 & 14.3 & 28.5 & 42.8 & 57.0 & 71.3 & 85.6 & 99.8 & 114.1 & 128.3 & 142.6 \\
\hline 1500 & 14.3 & 28.5 & 42.8 & 57.0 & 71.3 & 85.5 & 99.8 & 114.0 & 128.3 & 142.5 \\
\hline 2000 & 14.2 & 28.5 & 42.7 & 57.0 & 71.2 & 85.4 & 99.7 & 113.9 & 128.2 & 142.4 \\
\hline 2500 & 11.6 & 23.1 & 34.7 & 46.3 & 57.9 & 69.4 & 81.0 & 92.6 & 104.1 & 115.7 \\
\hline 3000 & 9.7 & 19.4 & 29.2 & 38.9 & 48.6 & 58.3 & 68.0 & 77.8 & 87.5 & 97.2 \\
\hline 4000 & 7.3 & 14.5 & 21.8 & 29.0 & 36.3 & 43.5 & 50.8 & 58.0 & 65.3 & 72.5 \\
\hline 5000 & 5.8 & 11.5 & 17.3 & 23.1 & 28.9 & 34.6 & 40.4 & 46.2 & 51.9 & 57.7 \\
\hline 6000 & 5.1 & 10.3 & 15.4 & 20.5 & 25.7 & 30.8 & 35.9 & 41.0 & 46.2 & 51.3 \\
\hline 7000 & 4.0 & 8.1 & 12.1 & 16.1 & 20.2 & 24.2 & 28.2 & 32.2 & 36.3 & 40.3 \\
\hline 8000 & 3.5 & 7.0 & 10.6 & 14.1 & 17.6 & 21.1 & 24.6 & 28.2 & 31.7 & 35.2 \\
\hline
\end{tabular}

The selected two motors are rated voltage $320 \mathrm{~V}$, the maximum power of $30 \mathrm{~kW}$ permanent magnet synchronous motor, its performance is shown in table 1 and figure 2, the motor's efficiency MAP is shown in figure 3 :

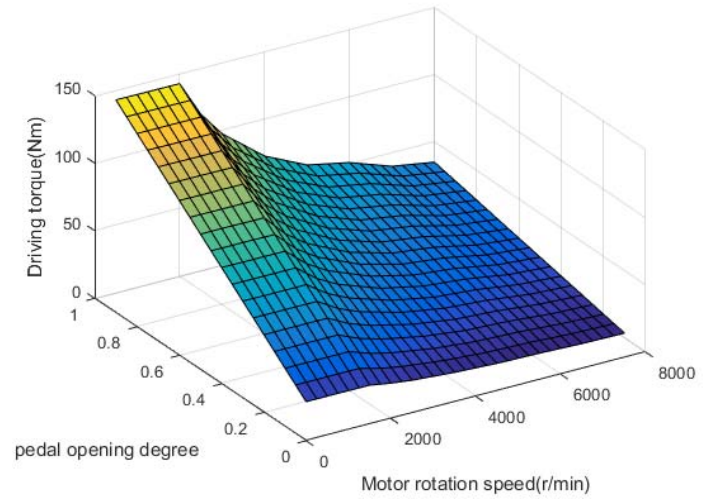

Figure 2. Motor torque output.

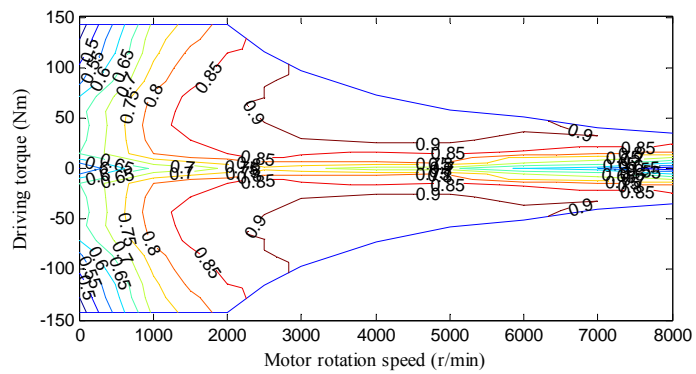

Figure 3. The motor's efficiency MAP.

\section{DRIVING TORQUE OPTIMIZATION ALLOCATION STRATEGY}

In this configuration, vehicle according to different working condition output the demand torque whose range from 0 to the sum of the peak torque of the motors (including driving and braking in both directions), the torque optimized allocation between the two motors can improve the overall driving efficiency. The total torque demand of the vehicle is two times of the torque in Table 1, which indicates that the main motor drive system of the invention can provide the maximum driving ability under different pedal opening degree.

The control strategy of the multi power integrated control system must decide how to allocate the vehicle target torque $T_{\text {req }}$ in the main motor torque $T_{m}$, the auxiliary motor torque $T_{a}$ the and the torque of the brake system $T_{\text {brake }}$ are reasonable and effective:

$T_{r e q} \leq 0$, The vehicle target torque is the braking torque (due to the vehicle brake is related to the national braking force distribution regulations and the vehicle real-time SOC status and other factors, the situation is more complex, so in this paper do not make specific analysis (Donateo T, et al., 2008; Deng Y, et al., 2008);

$T_{\text {req }}>0$, The vehicle target torque is the driving torque.

$T_{\text {req }}=T_{m}+T_{a}$

According to the motor driven power equation to allocate the vehicle torque, the goal is to minimize the total energy consumption of the system under the target torque requirement. In the following formula $\mathrm{T}$ is all of the motor torque distribution, $\mathrm{n}$ is the motor speed, $\eta$ stands for the motor drive efficiency under the corresponding rotational speed torque. Specific formula as follows:

$$
P_{m}=\sum \frac{T n}{9550 \eta}
$$

According to the optimal torque distribution strategy based on the powertrain equivalent consumption minimization (PESCM) [8] used in the hybrid electric vehicle to calculate the torque optimization for this configuration. Specific steps are as follows:

1) According to the current motor speed, the accelerator pedal opening degree and the pedal control of calibration curve to calculate the target torque;

2) Based on the calculated target torque, initially identified the master motor torque range, distribution candidate point and the corresponding efficiency;

3) According to the master motor torque calculated just now and formula (1) to determine the auxiliary motor torque and the corresponding efficiency;

4) Based on the formula (2) to calculate the total power consumption of the current drive; 
5) repeat2) - step4) to calculate all candidate points driving consumption total power, choose the optimal torque allocation scheme of the master and auxiliary motor.

Then the torque split maps of master and auxiliary motor could be obtained as follows:

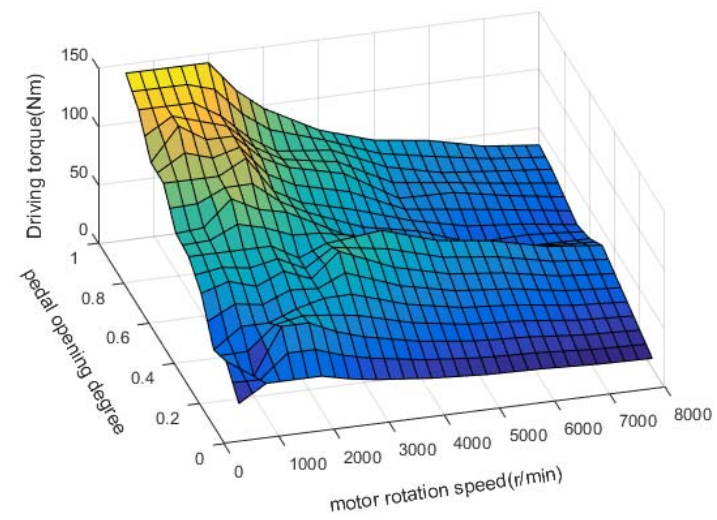

Figure 4. The torque split map of master motor.

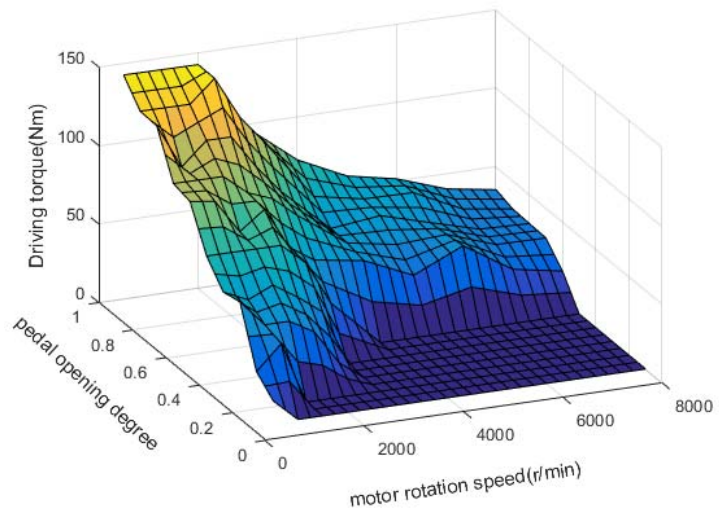

Figure 5. The torque split map of auxiliary motor.

\section{SIMULATION RESULTS VERIFY}

According to the vehicle parameters and vehicle dynamics theory, the system dynamics simulation model was built in MATLAB/Simulink as shown in Figure 6 below. What's more, the vehicle parameters are as follows:

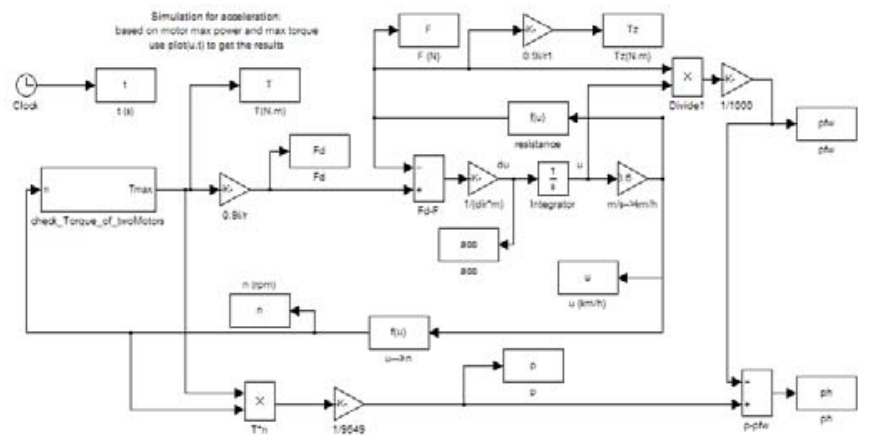

Figure 6 . The system dynamics simulation model.

\begin{tabular}{|l|l|l|l|l|l|l|l|}
\hline parameter & $\begin{array}{l}\text { Gross } \\
\text { vehicle } \\
\text { weight }\end{array}$ & $\begin{array}{l}\text { wheel } \\
\text { rolling } \\
\text { radius }\end{array}$ & $\begin{array}{l}\text { rolling } \\
\text { resistance } \\
\text { coefficient }\end{array}$ & $\begin{array}{l}\text { transmission } \\
\text { assembly } \\
\text { efficiency }\end{array}$ & $\begin{array}{l}\text { Transmission } \\
\text { assembly } \\
\text { ratio }\end{array}$ & $\begin{array}{l}\text { battery } \\
\text { voltage }\end{array}$ & $\begin{array}{l}\text { battery } \\
\text { capacity }\end{array}$ \\
\hline value & $1880 \mathrm{~kg}$ & $0.31 \mathrm{~m}$ & 0.33 & 0.92 & 6.6 & $320 \mathrm{~V}$ & $60 \mathrm{Ah}$ \\
\hline
\end{tabular}

Figure 7. The vehicle parameters.

By comparing the efficiency interval of the torque optimization (Figure 8) and equal torque allocation (Figure 9) for this configuration, we can know the former expand the efficient working range, improve the energy conversation potential.

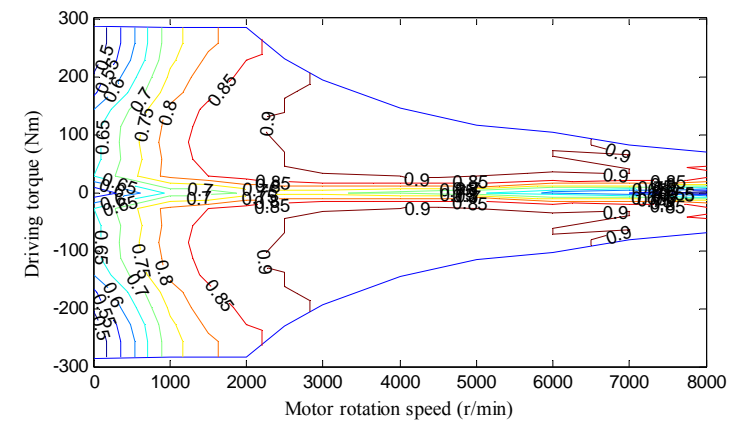

Figure 8. The efficiency interval of the torque optimization.

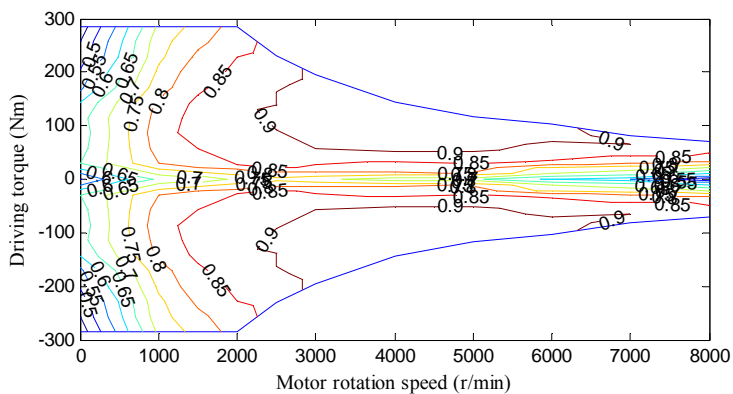

Figure 9. The efficiency interval of equal torque allocation.

\section{COUPLING DRIVING ANALYSIS IN CONCRETE WORKING CONDITIONS}

Select UDDS standard urban conditions for analysis and comparison, the specific conditions shown in figure 10 .

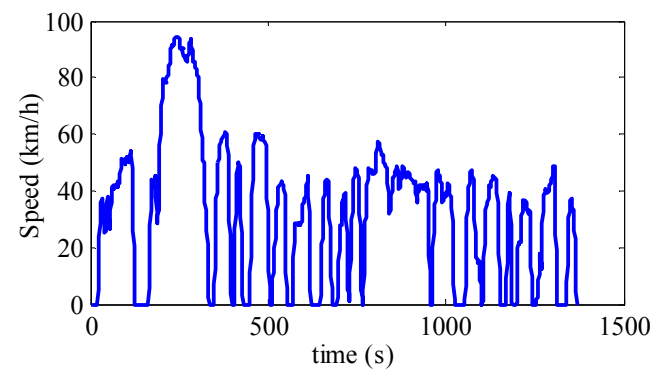

Figure 10. UDDS standard urban conditions. 
The vehicle driving range can reach $130.1 \mathrm{~km}$ with the torque optimization, the operating points of master and auxiliary motor as shown in figure 11, 12 ; while $122.7 \mathrm{~km}$ with the equal torque allocation, the operating points of master and auxiliary motor as shown in figure 13.

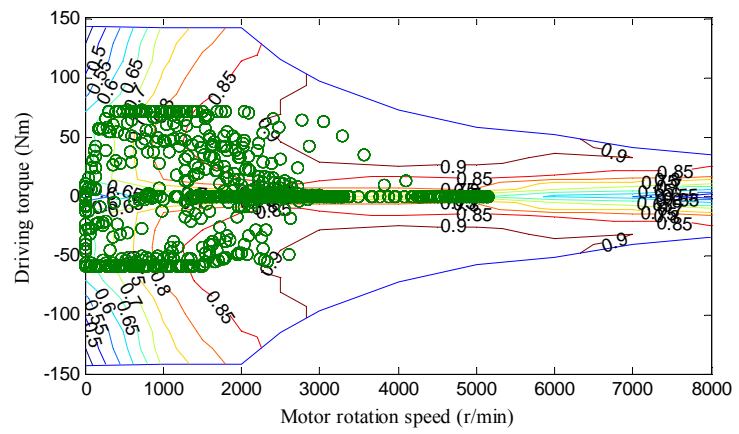

Figure 11. Operating points of master motor.

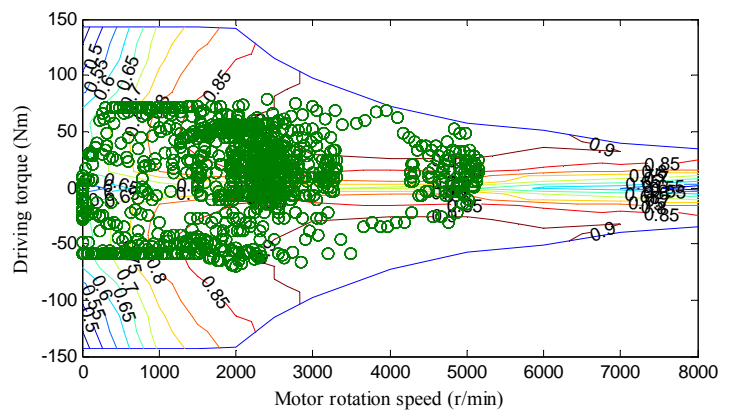

Figure 12 . Operating points of auxiliary motor

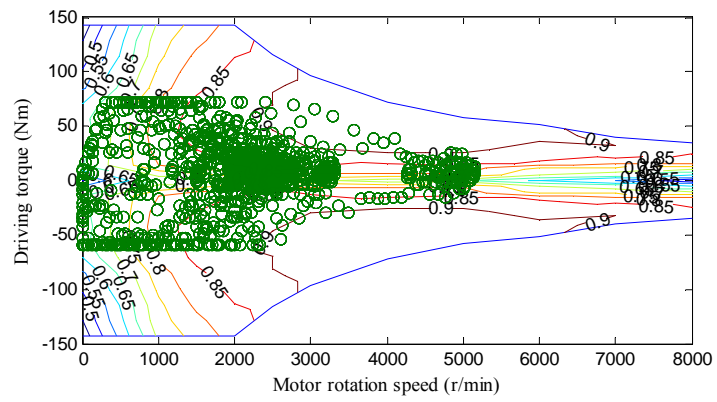

Figure 13. Operating points motor (the equal torque allocation).

\section{CONCLUSION}

The results show that the master and auxiliary motor coupled driving system with the torque optimization compared with the equal torque allocation can dramatically expand the efficient working range so that the motor operating point can be more into the high efficient range; In UDDS standard urban conditions, the vehicle's driving range has increased by $6 \%$ with that torque optimization. Such conditions demand vehicle drive torque is small, when the higher speed or torque demand is large, the vehicle driving efficiency will be further improved.

\section{REFERENCE}

Bo Zhu, Nong, Zhang, Paul Walker et al. Two Motor Two Speed Power-Train System Research of Pure Electric Vehicle[C].//SAE 2013 world congress and Exhibition: April 1618, 2013, Detroit, Michigan, USA.2013:12391-12395.

Donateo T, Serrao L, Rizzoni G. A two-step optimisation method for the preliminary design of a hybrid electric vehicle $[\mathrm{J}]$. International Journal of Electric and Hybrid Vehicles, 2008, 1(2): 142-165.

Deng Y, Gong J, Yang J, et al. An investigation on energy optimisation of the CFA6470 parallel hybrid electric vehicle $[\mathrm{J}]$. International Journal of Electric and Hybrid Vehicles, 2008, 1(2): 166-187.

GAO Jian-ping, HE Hong-wen, SUN Feng-chun. Classification of Electromechanical Coupling Systems in Hybrid Electric Vehicles [J].Transactions of Beijing Institute of Technology,2008,28(3).

Wu Xiaohua, Yin Xiaofeng. Control of a dual-motor coupling drive system on EV buses [J]. Chinese High Technology Letters, 2013,23(8).

WANG Jun-nian, LIU De-chun. Analysis of energy conservation potential of novel pure electric vehicle with dual motors configuration [J].Journal of Jilin University (Engineering and Technology Edition),2016,46(1).

Wang Feng. Fang Zongde. Zhu Xiaoyuan. Matching, Simulation and Optimization of the New Power Transmission Device for an Electric Vehicle [J]. Automotive Engineering, 2011, 33(9).

Wang Feng, Mao, Xiaojian, Zhuo Bin, Torque Distribution for an Integrated Starter Generator Parallel Hybrid Electric Car[J]. Journal of Chongqing University (Natural Science Edition), 2008, 31(5):499-504.

Zeng Xiaohua,Wang Qingnian,Wang Weihua,et al.Effect on the Cost of Parallel HEB for Different DOH[J].Transactions of the Chinese Society for Agricultural Machinery, 2008, 39(1):15-19. 